STRATEGIC HELPER

\title{
The strategic helper: Narcissism and prosocial motives and behaviors
}

\author{
Sara Konrath ${ }^{1,2,3}$ \\ Meng-Han $\mathrm{Ho}^{1}$ \\ Sasha Zarins ${ }^{1}$
}

1. Indiana University, Lilly Family School of Philanthropy

2. Institute for Social Research, University of Michigan

3. Department of Psychiatry, University of Rochester Medical Center

\begin{abstract}
Author note: Address correspondence to Sara Konrath, Lilly Family School of Philanthropy, Indiana University, 550 W North Street, Indianapolis, 46202. Email: skonrath@iupui.edu. This project was supported by grants from the John Templeton Foundation (\#47993 and 57942) and Wake Forest University, The Character Project. The authors declare that they have no conflicts of interest.
\end{abstract}

This is the author's manuscript of the article published in final edited form as:

Konrath, S., Ho, M.-H., \& Zarins, S. (2016). The Strategic Helper: Narcissism and Prosocial Motives and Behaviors. Current Psychology, 35 (2), 182-194. http://doi.org/10.1007/s12144-016-9417-3 


\begin{abstract}
Across three studies, we examined the relationship between narcissism, prosocial behaviors, and the reasons why people engaged in them. Specifically, we examined how narcissistic people engaged in charitable donations, taking advantage of a naturally occurring mass charitable donation campaign, the ALS “ice bucket challenge” (Study 1). We also examined how narcissism was related to volunteering and other types of prosocial behaviors (Studies 2 and 3). Moreover, we compared and contrasted the prosocial responses of more empathic versus more narcissistic people (Studies 2 and 3). This paper can help scholars and practitioners to determine under which circumstances, and for which reasons, narcissistic people may exhibit prosocial behaviors.
\end{abstract}

Abstract word count: $<106>$

Keywords: narcissism, prosocial behavior, empathy, charitable donations, volunteering, motives for volunteering, helping 
“To give without any reward, or any notice, has a special quality of its own." Anne Morrow Lindbergh

Compared to research on narcissism and aggression, there is much less research on narcissism and prosocial behavior. Prosocial behavior is defined as actions intended to benefit others, and it includes a wide range of behaviors such as cooperating, sharing, giving, helping, and comforting others (Batson \& Powell, 2003). Prosocial behaviors can sometimes be altruistic, which is defined as "self-sacrificial helping, or helping in the absence of obvious, external rewards” (Batson \& Powell, 2003). However, altruism is a motivation and not a behavior, and there are other egoistic reasons for prosocial behavior such as to receive praise or attention, to reduce uncomfortable feelings such as guilt, or to receive something in return (Batson, 2011). Prosocial behaviors can take many different forms, but in general, they can be separated into more informal, everyday prosocial acts outside of formal organizational settings (e.g., letting someone ahead in line; comforting someone who is sad), versus behaviors that occur within more formal, organizational settings, such as volunteering or donating money to charitable organizations. In the current paper, we examined the relationship between the personality trait narcissism and both formal and informal prosocial behaviors and motives.

\section{Narcissism and prosocial behavior}

Narcissism is a personality trait characterized by excessively high self-esteem and relatively low empathy (Miller \& Campbell, 2008; Watson, Grisham, Trotter, \& Biderman, 1984). Increased narcissism is associated with more self-enhancement on agentic traits like intelligence and extraversion rather than communal traits like agreeableness and morality (Campbell, Rudich, \& Sedikides, 2002; Paulhus \& John, 1998). There is a robust literature on the interpersonal implications of narcissism. More narcissistic people have difficulties in maintaining close relationships (Campbell \& Foster, 2002) and are hostile and aggressive, especially when their egos are threatened (Bushman \& Baumeister, 1998; Fukunishi, Hattori, Nakamura, \& Nakagawa, 1995; Konrath, Bushman, \& Campbell, 2006; Reidy, Zeichner, Foster, \& Martinez, 2008; Twenge \& Campbell, 2003).

However, only a few studies have directly assessed the relationship between narcissism and prosocial behaviors and motivations. Research on this topic may be so limited because there is an assumption that if narcissism is associated with more antisocial behavior, it must also be associated with less prosocial behavior. However, antisocial behavior and prosocial behavior are not opposite processes. Prosocial behavior is more common and socially normative than antisocial behavior. Moreover, people may behave prosocially for a variety of reasons, and one cannot assume that the presence of prosocial behavior necessarily implies altruistic motives and compassionate emotions.

The Extended Agency Model can help to guide predictions about in which situations, and for which reasons, narcissistic people might act prosocially (Campbell \& Foster, 2007). This model posits that narcissism intensifies the rewards experienced from agentic situations such as from having high status and power, while also dampening the rewards from communal experiences such as from having warmth and connection with others. Such a system would lead to an increased focus on success, power, and attention, and a decreased focus on caring for others. Campbell and Foster suggest that the output of such a system is an ever increasing need for narcissistic esteem (i.e. proud and dominant feelings), which can be achieved in a variety of ways such as by bragging, showing off, or seeking attention. 
Based on this model, we would expect that more narcissistic people would be more likely to engage in prosocial behaviors in order to increase their narcissistic esteem through attention or praise, for example, by giving when others are watching. More narcissistic people should also be more likely to engage in prosocial behaviors in a calculating way that is sensitive to the costs versus benefits of giving or helping. This could be achieved by either reducing the cost of prosocial behavior by engaging in relatively low-effort "slacktivism" activities such as posting or sharing a message on social networks (Kristofferson, White, \& Peloza, 2014) or by increasing the potential benefits by being more likely to help when there are current or future rewards. Many people help for the simple reason that others are in need. Yet because more narcissistic people prioritize agency over communal concerns, the motivation to take care of others' needs is likely to be less intrinsically important and rewarding to them. Instead, more narcissistic people are likely to act prosocially as a means to some other end. Thus, in this paper we hypothesize that narcissistic people will be more likely to act prosocially in situations when they can receive something in return, such as attention, praise, or a returned favor.

In terms of frequency of prosocial behaviors, the evidence is mixed. Although some studies have found that more narcissistic people report more frequently engaging in prosocial behaviors (Kauten \& Barry, 2014; Zhou, Zhou, \& Zhang, 2010), another study finds that people who score higher in narcissistic entitlement are less likely to volunteer for nonprofit organizations (Brunell, Tumblin, \& Buelow, 2014). Yet these studies measured prosocial behaviors in general, rather than specifically asking which situations elicit them or why people engaged in them. Indeed, one other study found that narcissism is specifically associated with more self-serving prosocial behaviors. For example, more narcissistic people were more likely to say that they helped in public settings, when others could see them, and that they helped opportunistically, when they could receive something in return, such as a returned favor, attention or praise, a line on their resume, or some other reward (Eberly-Lewis \& Coetzee, 2015). Therefore, more narcissistic people may only engage in prosocial behaviors in certain situations, such as when an audience is present, since acting prosocially in public can enhance their image.

External features of the situation may influence whether more narcissistic people will engage in prosocial behavior, but so might their internal motivations. Yet the literature on narcissism and motivation for prosocial behavior is limited. In terms of more formal and longterm prosocial behaviors such as volunteering for non-profit organizations, there are many different reasons why people get involved, ranging from those that are more focused on helping others to those that are more focused on receiving personal benefits, such as promoting one's career (Clary et al., 1998). To our knowledge, there is only one paper that has examined narcissism and motives for volunteering (Brunell et al., 2014). It found that among active volunteers, more narcissistic people prioritized career-oriented concerns (Career motive), escaping their own problems (Protective motive), and social concerns (Social motive). These few prior studies rely on self-report measures of prosocial behaviors, and the situations and motives that elicit them.

There is limited research examining narcissism and actual prosocial behavioral responses. These studies found that narcissism (especially narcissistic exploitativeness) was associated with a greater tendency to harvest more natural resources (i.e., forests) in hypothetical resource dilemma games, which in turn, depleted these resources for the larger community (Brunell et al., 2013; Campbell, Bush, Brunell, \& Shelton, 2005). In other words, more narcissistic people behaved more selfishly and less prosocially in these games. One other major gap in the literature 
is in the domain of charitable donations. No studies that we are aware of have examined the charitable donation behaviors of more narcissistic people.

\section{Dispositional empathy and prosocial behavior}

Dispositional empathy is the chronic tendency to respond to the feelings and perspectives of others (Davis, 1983). Empathic concern represents the more emotional form of empathy, while perspective taking represents the more cognitive form of it (Davis, 1983). Both types of empathy predict a greater likelihood of volunteering and other prosocial behaviors (Borman, Penner, Allen, \& Motowidlo, 2001; Eisenberg \& Miller, 1987; Underwood \& Moore, 1982). Moreover, dispositional empathic concern and perspective taking are both associated with more altruistic motives for volunteering (Davis, Hall, \& Meyer, 2003). Individuals scoring higher in narcissism report lower empathic concern and perspective taking (Watson et al., 1984; Watson \& Morris, 1991), which we believe would diminish the likelihood that they would respond with care and concern to others in need.

Since empathy is an important motivator of prosocial behavior, we also examined the similarities and differences in the prosociality of more empathic versus more narcissistic people in the current paper (Study 3). Only one previous study that we are aware of has done this. When comparing empathy and narcissism as predictors of self-reported prosocial behavior, it found that more empathic people reported fewer public and opportunistic prosocial behaviors (i.e., helping to look good) while more narcissistic people reported more public and opportunistic prosocial behaviors (Eberly-Lewis \& Coetzee, 2015). Therefore, even though both empathy (Borman et al., 2001; Eisenberg \& Miller, 1987; Underwood \& Moore, 1982) and narcissism (Kauten \& Barry, 2014; Zhou et al., 2010) are positively associated with self-reported prosocial behaviors, there are differences in the types of situations that typically elicit such prosocial behaviors. However, no research has examined to what extent they differentially predict motives for volunteering. We address this question in the current paper (Study 3 ).

\section{The current paper}

In this paper, we examined the relationship between narcissism and prosocial behaviors. As summarized above, there is only limited research examining the relationship between narcissism and prosocial behavior and we aimed to conceptually replicate and extend these findings. Specifically, we examined the relationship between narcissism and charitable donations (Study 1), which is a novel contribution of this paper. We also examined the relationship between narcissism and the frequency of volunteering (Study 2), community involvement (Study 2), and prosocial behaviors in general (Study 3). Finally, we examined the situations (EberlyLewis \& Coetzee, 2015) and motives (Brunell et al., 2014) that elicit prosocial behavior in more narcissistic people, again aiming to conceptually replicate and extend previous work.

In Study 3, we also controlled for the role of social desirability in the narcissismprosocial behavior relationship, which is another novel contribution. Social desirability is either unrelated or negatively related to narcissism (Watson et al., 1984; Watson \& Morris, 1991), and is also positively associated with empathy (Paulhus \& Reid, 1991; Watson \& Morris, 1991). This suggests that more narcissistic people may be less likely to care about looking morally good or genuinely altruistic to others, which is in line with the Extended Agency Model (Campbell \& Foster, 2007). It is thus important to control for social desirability in studies examining the relationship between empathy, narcissism, and prosocial behavior. Narcissistic people are clearly sensitive to the presence of others, since they act differently when in public versus alone (e.g. Ferriday, Vartanian, \& Mandel, 2011; Wallace \& Baumeister, 2002); they need others as 
important sources to help build their narcissistic esteem. However, the attention from others need not be focused on the genuineness of their prosocial behaviors.

Study 3 additionally compared the motives for volunteering reported by more empathic (both cognitive and emotional empathy) versus more narcissistic people. Because gender is associated with narcissism, empathy, and prosocial behaviors (Eagly, 2009; Foster, Keith Campbell, \& Twenge, 2003; Grühn, Rebucal, Diehl, Lumley, \& Labouvie-Vief, 2008), in all studies we report analyses both with and without controlling for gender. Taken together, we take a more comprehensive approach to prosocial behavior than prior research, which can help scholars and practitioners to determine under which circumstances, and for which reasons, more narcissistic people may exhibit prosocial behavior.

\section{Study 1 Overview}

In Study 1 we took advantage of a naturalistic situation to examine how narcissism was related to different responses to a major charitable donation campaign. The ALS “ice bucket challenge" was a fundraising campaign for a nonprofit organization that went viral in summer 2014. The ice bucket challenge was widely known about and discussed, with 17 million videos about it posted on Facebook between June 1 and Sept 1, 2014. These videos were viewed over 10 billion times by 440 million people (Facebook.com, 2014). The ALS Association received almost 34 times the amount of donations in Aug 2014 (\$94.3 million) than they did in Aug 2013 (\$2.7 million), representing 2.1 million new donors (Munk, 2014). We examined whether narcissism was related to the type of commitment exhibited in response to the ice bucket challenge.

\section{Study 1 Method}

Participants. Participants were 9062 adults recruited between August 24 and September 3, 2014 (Mean age= 37.73, $S D=12.99$, range=18 to 84; 64\% female). Participants were recruited from an ongoing online survey posted on the first author's website. The survey allows participants to receive personalized feedback on their narcissism levels. Participants completed the survey voluntarily and without payment.

Measures. Participants were first asked a question about their behavior related to the ALS ice bucket challenge. They read this note: "This summer, there has been a lot of media attention for the "ALS ice bucket challenge." In the ALS ice bucket challenge, people are challenged to either dump a bucket of ice water over their head or donate \$100 to the ALS Association. After getting water dumped on their head, they then post the video online and challenge their friends." They were next asked to report their personal level of involvement with the ice bucket challenge. Participants could choose from the following response options:

1) Have not heard about the ice bucket challenge ( $N=302 ; 3.3 \%)$,

2) Heard of it, but not challenged ( $N=6562 ; 72.4 \%)$,

3) Challenged, but did not participate ( $N=1288 ; 14.2 \%)$,

4) Made a donation only $(N=237 ; 2.6 \%)$,

5) Posted an ice bucket video of themselves online only ( $N=336 ; 3.7 \%)$, and

6) Both donated and posted an ice bucket video ( $N=337 ; 3.7 \%)$.

Participants then completed the Single Item Narcissism Scale (Konrath, Meier, \& Bushman, 2014), which assesses trait narcissism using a single item (1=not at all true of me; 7=very true of me): "To what extent do you agree with this statement: I am a narcissist. (Note: The word 'narcissist' means egotistical, self-focused, and vain.).” This scale is correlated with longer narcissism scales, is stable over time, and predicts similar outcomes as longer narcissism scales (Konrath, Meier, et al., 2014). 


\section{Study 1 Results}

Descriptive statistics. The average narcissism score was 2.88 ( $S D=1.48$, range $=1$ to 7$)$. Only 2198 respondents (24.3\% of the total sample) were challenged to do the ice bucket challenge. The most common response for those people who were challenged was to do nothing ( $N=1288$; $58.6 \%$ of those who were challenged).

Ice bucket challenge and narcissism. We first ran an ANOVA with the six response options as the predictor variable and narcissism as the dependent measure. Although Study 1 uses cross-sectional data and we are not making claims that donations (independent variable) cause changes in narcissism levels (dependent variable), this statistical strategy makes sense, given the categorical nature of the donation responses. Indeed, results remain similar if we reverse these variables so that narcissism is predicting donation or posting behavior.

As can be seen in Figure 1, participants' responses to the ice bucket challenge were related to their narcissism scores, $F(4,9056)=4.90, p<.001$. Post-hoc LSD tests revealed that participants who only donated money had the lowest narcissism scores $(M=2.68, S D=1.41)$, scoring significantly lower than those who posted a video only $(M=3.14, S D=1.61, d=.30)$, those who both donated and posted a video $(M=2.99, S D=1.43, d=.22)$, and those who were challenged but did not participate $(M=2.98, S D=1.51, d=.21), p s<.02$, and marginally lower than those who heard about it but were not challenged $(M=2.86, S D=1.47, d=.12), p=.065$. Participants who only donated money scored lower than those who had not heard of the ice bucket challenge $(M=2.85$, $S D=1.60, d=.11$ ), but this difference did not reach significance, $p=.13$.

Participants who only posted videos had the highest narcissism scores, differing significantly from those who only donated money $(d=.30)$, those who were not challenged $(d=.18)$, and those who had not heard about the challenge $(d=.18), p s<.02$. Those who only posted videos scored marginally higher than those who were challenged but did not participate ( $d=.10), p=.09$, and non-significantly higher than those who both donated and posted a video $(d=.10), p=.11$.

Most respondents knew about the ice bucket challenge, but only some of them were directly challenged. We were especially interested in knowing whether their responses to that challenge was related to their narcissism levels. Thus, the next analysis focused on only those who had been challenged $(N=2198)$. We first recoded their responses into two separate behaviors: Donation (Yes / No) or Video Posting (Yes / No). We next ran a 2x2 ANOVA with Donation (Yes / No) and Video Posting (Yes / No) as the predictor variables and narcissism as the dependent measure.

Both main effects were significant. First, those who posted an ice bucket challenge video online scored higher in narcissism $(M=3.06, S D=1.52)$ than those who did not post a video $(M=2.94, S D=1.50), F(1,2194)=8.68, p=.003$. Next, those who made a donation scored lower in narcissism $(M=2.86, S D=1.43)$ than those who did not make a donation $(M=3.02, S D=1.53)$, $F(1,2194)=8.57, p=.003$. There was no interaction between posting the video and making a donation, $F(1,2194)=2.25, p=.32$. All results remained consistent when controlling for gender.

\section{Study 1 Discussion}

There were many different possible responses that people could have after they learned about the ice bucket challenge. In Study 1, we found that those who posted a video of themselves online having a bucket of ice water dumped on their heads scored significantly higher in narcissism compared to those who did not post a video. In addition, those who responded to the ice bucket challenge by making a donation to the ALS Association scored significantly lower in narcissism than those who did not. Making a donation is a much more private behavior than 
posting an online video, and we suspect that more narcissistic people were motivated by the attention that they would receive by posting the video online. However, this study did not directly assess why higher narcissism was associated with such different responses to the ice bucket challenge. In addition, Study 1 used a new single-item measure of narcissism, rather than a more established, longer measure of it. Thus, in Studies 2 and 3 we addressed these issues by using a longer measure of narcissism and by directly asking about the motives and situations that elicit prosocial behavior.

\section{Study 2 Overview}

In Study 2, we measured narcissism and also assessed formal prosocial behavior (i.e., volunteering and community involvement) and different situations that evoke prosocial behavior (e.g., being watched, emergencies, and being asked). In terms of formal prosocial behavior, we were unsure what to expect. On the one hand, one study found that people who scored higher in narcissistic exploitativeness were less likely to report volunteering in the past year (Brunell et al., 2014). On the other hand, other aspects of narcissism, including grandiosity, were unrelated to the probability of volunteering (Brunell et al., 2014). Since we assess grandiose narcissism in the current paper, it is possible that there will be no differences in the narcissism levels of people who volunteer or help in the community compared to those who do not. Considering that there are many reasons to volunteer, it is possible for both more and less narcissistic people to decide to volunteer. For example, many schools now require students to complete a certain number of volunteer hours. In terms of situations that elicit helping, we hypothesize that more narcissistic people will be more likely to help in situations where they can gain attention or some other reward, rather than helping for more altruistic reasons.

\section{Study 2 Method}

Participants. Participants were 289 undergraduates at a large Midwestern university who completed an online survey for credit (74\% female; Mean age=18.9, $S D=.80$; range=17 to 23). Since participants did not always complete all scales, the Ns slightly vary in the analyses.

Measures. The reported measures were embedded within a larger mass testing survey. We measured narcissism using the 16-item Narcissistic Personality Inventory (Ames, Rose, \& Anderson, 2006). Participants were given two statements: one that was less narcissistic (e.g., "Sometimes I am not sure of what I am doing.") and one that was more narcissistic (e.g., "I always know what I'm doing"). They rated to what extent each statement was self-descriptive (1=lowest narcissism, $7=$ highest narcissism). We calculated a total narcissism score by averaging the items $(\alpha=.86)$. Note that the Cronbach's alphas in the original scale development paper ranged from $\alpha=.65$ to .72 (Ames et al., 2006).

To assess volunteering and community involvement, participants were asked two questions assessing how often they had volunteered for a nonprofit organization and whether they had worked on a community project in the past 12 months $(0=$ none in the past year; $7=$ more than once per week). The 23-item Prosocial Tendencies Scale assessed six types of helping (Carlo \& Randall, 2002). Public prosocial behaviors include those that are done primarily in the presence of others ( 4 items; $\alpha=.82$; "I can help others best when people are watching me"). Dire prosocial behaviors involve helping during emergencies or extreme situations ( 3 items; $\alpha=.72$; " $I$ tend to help people who are in real crisis or need"). Emotional prosocial behaviors are done primarily during emotional situations ( 4 items; $\alpha=.78$; "I respond to helping others best when the situation is highly emotional"). Compliant prosocial behaviors occur after being asked (2 items; $\alpha=.75$; "When people ask me to help them, I don't hesitate"). Anonymous prosocial behaviors occur without others' knowledge (5 items; $\alpha=.82$; "I think that helping others without them 
knowing is the best type of situation"). Finally, opportunistic prosocial behaviors occur when the helper can personally benefit, rather than when others are in need ( 5 items; $\alpha=.80$; "I feel that if I help someone, they should help me in the future."). The scale endpoints were $1=d o e s$ not describe me at all to 5=describes me greatly.

\section{Study 2 Results}

Descriptive statistics. The average narcissism score in the sample was $3.99(S D=.89)$. See Table 1 for descriptive statistics and raw intercorrelations between the other variables.

Data analysis plan. We ran a single regression analysis to examine to what extent the prosocial variables (volunteering, community involvement, and each of the six different kinds of prosocial behaviors) were uniquely associated with narcissism. In Step 1 of the regression we entered the eight prosocial variables as predictor variables and narcissism as the outcome variable, and in Step 2, we entered gender as a covariate.

Prosocial behavior and narcissism. As can be seen in Table 2, there was no relationship between overall narcissism and the frequency of volunteering behavior, and this did not change when controlling for gender. There is also no relationship between narcissism and the frequency of community project involvement, and again, this does not change when controlling for gender. When it comes to the different types of prosocial behavior, more narcissistic people were more likely to engage in Public prosocial behaviors, and less likely to engage in Anonymous prosocial behaviors. There was also a tendency for more narcissistic people to engage in more Emotional prosocial behaviors, and more narcissistic people were marginally less likely to engage in Compliant prosocial behaviors. There was no independent relationship between narcissism and Dire or Opportunistic prosocial behaviors. All results remained similar when controlling for gender.

\section{Study 2 Discussion}

Study 2 found that narcissism was unrelated to the frequency of volunteering or community project involvement. We suspect that this is because there are many reasons to volunteer, some of which are more focused on others' needs and some of which are more focused on the potential for personal gain. Study 3 attempted to directly address this question.

In terms of other types of prosocial behaviors, the raw correlations in Study 2 replicated a prior study finding that more narcissistic people are more likely to engage in public and opportunistic prosocial behaviors (Eberly-Lewis \& Coetzee, 2015). In other words, more narcissistic people prefer to help when others can see them or when they can receive something in return. Yet opportunistic prosocial behaviors no longer independently predicted narcissism when all other prosocial variables were included in the model. This likely because of the high correlation between opportunistic and public prosocial behaviors $(r=.70)$, which may have made it difficult to detect the independent effects. This may suggest that the specific ways that more narcissistic people engage in opportunistic prosocial behaviors is by doing so in public, and by being less likely to help others anonymously. These results fit with those of Study 1, by again demonstrating the importance of the potential to receive attention for prosocial acts.

There was also a tendency for more narcissistic people to engage in emotional prosocial behaviors, which indicates that more narcissistic people are more likely to help after seeing strong signals of distress. This was an unexpected finding, and should be further explored in future research. Previous research has found that people who score high in narcissistic exploitativeness are better at recognizing negative emotions in others (Konrath, Corneille, Bushman, \& Luminet, 2014). The authors speculate that this may be because more exploitative people are better attuned to vulnerability in others so that they can take advantage of it. But 
Study 2 suggests that at times signals of vulnerability in others (i.e. distress) may promote helping behavior among more narcissistic people. Perhaps more narcissistic people enjoy the feeling of being a "hero" and "rescuing" people in distress. Future studies should vary the level of emotional distress and the audience (alone versus in public) to examine under which situations more narcissistic people are likely to help.

Finally, Study 2 found that more narcissistic people were marginally less likely to help after being asked. However, since this was not as robust as the other findings, we do not discuss it further. Taken together, these results specify under which conditions more narcissistic people may be likely to help others. People who score higher in narcissism may be just as willing to volunteer for nonprofit organizations as others, but they prefer to engage in prosocial activities that can be seen by others, rather than anonymously. They also prefer to help after seeing strong signals of distress in others.

\section{Study 3 Overview}

Study 3 can further increase our understanding of the prosocial behavior of more narcissistic people by asking about the frequencies of other kinds of prosocial behaviors, not just formal prosocial behaviors such as volunteering or community involvement. Study 3 also directly measured participants' self-reported motives for volunteering, rather than inferring motivations based upon the types of helping behaviors that they engage in. We further sought to examine whether social desirability played a role in the relationship between narcissism and prosociality. Thus, we controlled for it in Study 3. Finally, in Study 3 we compared the responses of people scoring high in narcissism to those scoring high in dispositional empathic concern and perspective taking.

\section{Study 3 Method}

Participants. Following an IRB-approved protocol, undergraduates in an advanced research methods class at a large Midwestern university recruited a large sample of participants using flyers, social network posts, email requests, and personal invitations. The final sample included 819 adults who responded to an online questionnaire with measures related to narcissism, prosociality, media usage, health, and well-being. Nineteen people did not respond to the narcissism measure, so they were excluded from further analyses, leaving a final sample of 800 (Mean age $=27.86, S D=13.86$, range $=18$ to $82 ; 73.6 \%$ female; $84.3 \%$ Caucasian). The sample was highly educated, with $87.5 \%$ of the population having at least some college. The sample was also relatively high income: the average gross annual household income was in the $\$ 75,000$ to $\$ 99,999$ range. Note that the exact number of participants in each analysis varies slightly depending on the number of respondents for each scale.

Measures. The measures used in this study were embedded within the larger battery of questionnaires. Narcissism was measured using the original forced-choice version of the NPI-16 (Ames et al., 2006). For each of 16 items, participants chose the statement that best applied to them from two choices ( $0=$ non-narcissistic, e.g., "Sometimes I am not sure of what I am doing"; 1=narcissistic, e.g., "I always know what I'm doing”). We calculated a total narcissism score by summing the narcissistic items $(\alpha=.73)$.

Dispositional empathy was assessed using two 7-item subscales of the Interpersonal Reactivity Index (Davis, 1983). Empathic Concern involves more emotional aspects of empathy, measuring people's tendency to feel compassion and care for those in need: (e.g., "I often have tender, concerned feelings for people less fortunate than me”; $\alpha=.79$ ). Perspective Taking involves more cognitive aspects of empathy, measuring people's tendency to imagine others' thoughts and viewpoints (e.g., "I sometimes try to understand my friends better by imagining 
how things look from their perspective"; $\alpha=.79$ ). For both subscales, the scale endpoints were $1=$ does not describe me very well; $5=$ describes me very well.

The prosocial behaviors measure was taken from the 2002 General Social Survey altruism module (Smith, Marsden, Hout, \& Kim, 2013). Participants were asked how often in the past 12 months they performed 17 different prosocial behaviors $(1=$ not at all in the past year, 6=more than once a week; e.g., Gave food to a homeless person, Helped somebody find a job). We averaged the items, such that higher numbers indicated more frequent prosocial behaviors $(\alpha=.81)$.

Motives for volunteering were assessed using a 12-item version of the Volunteer Functions Inventory (Clary et al., 1998). Participants responded to 2 items for each of six potential motives for volunteering: Altruistic (e.g., "I feel compassion toward people in need;" $\alpha=.85$ ), Social (e.g., "Others with whom I am close place a high value on community service;" $\alpha=.89$ ), Career (e.g., "I can make new contacts that might help my business or career;" $\alpha=.86$ ), Esteem (e.g., "Volunteering makes me feel better about myself;" $\alpha=.81$ ), Understanding (e.g., "I can explore my own strengths;" $\alpha=.70$ ), and Protective (e.g., "Volunteering is a good escape from my own troubles;" $\alpha=.84$ ). Participants were asked to indicate how important or accurate each of these reasons were (or would be) for volunteering (1=not at all important / accurate for you; 7=extremely important / accurate for you).

Social desirability was measured by summing the 10-items of the shortened MarloweCrowne Social Desirability Scale (Strahan \& Gerbasi, 1972). A sample item is "I never hesitate to go out of my way to help someone in trouble" $(\alpha=.60 ; 1=$ socially desirable response, $0=$ less desirable response). Note the low Cronbach alpha for this scale. In the original scale development paper, the alphas in four studies were: .49, .62, .62, and .75 (Strahan \& Gerbasi, 1972). Such low reliabilities are to be expected when using shorter scales, and researchers should use longer scales in future work. We caution readers to consider these issues when interpreting these results.

\section{Study 3 Results}

Descriptive statistics. See Table 3 for descriptive statistics and raw intercorrelations between the variables.

Data analysis plan. We ran three separate regression analyses to examine to what extent the prosocial variables (frequency of prosocial behaviors, and each of the six motives for volunteering) were uniquely associated with narcissism. In Step 1 of the regression we entered the seven prosocial variables as predictor variables and narcissism as the outcome variable, and in Step 2, we entered gender and social desirability as covariates. Z-scores were calculated to create comparable scales for the analysis. See Table 4 for the standardized betas and significance levels.

Narcissism. People who scored higher in narcissism reported more frequent prosocial behaviors, less importance of altruistic motives for volunteering, and marginally more importance of understanding motives for volunteering (See Table 4). As can be seen in Table 4, these results remained similar when controlling for gender and social desirability. Gender was significantly associated with narcissism, $\beta=.17, \mathrm{p}<.001$, with males scoring higher than females, as per prior research (Foster et al., 2003). In addition, more narcissistic people scored lower in social desirability, $\beta=-.10, p=.004$, also replicating prior research (Konrath, Meier, et al., 2014).

Perspective Taking. People who scored higher in perspective taking reported more frequent prosocial behaviors, more importance of altruistic motives for volunteering, and marginally less importance of esteem motives for volunteering. No other effects emerged as 
significant (See Table 4). The results remained similar when controlling for gender and social desirability, with two minor exceptions. When adding the covariates, perspective taking became marginally associated with less importance of social motives, and was also no longer significantly associated with esteem motives. However, all effects remained in the same direction and only changed by betas of between .00-.04, suggesting that the influence of gender and social desirability is minor.

Unlike in prior research (O’Brien, Konrath, Grühn, \& Hagen, 2013), gender was unrelated to perspective taking, $\beta=.00, p=.96$. However, perspective taking was significantly associated with higher social desirability, $\beta=.26, \mathrm{p}<.001$, as has been found in prior research (Watson \& Morris, 1991).

Empathic Concern. People who scored higher in empathic concern reported more frequent prosocial behaviors, more importance of altruistic motives for volunteering, and marginally more importance of protective motives for volunteering. More empathic concern was also associated with less importance of social and career motives for volunteering. As can be seen in Table 4, these results remained similar when controlling for gender and social desirability.

Gender was significantly associated with empathic concern, $\beta=-.12$, $\mathrm{p}<.001$, with males scoring lower than females as per prior research (O’Brien et al., 2013). In addition, empathic concern was positively associated with social desirability, $\beta=.13, \mathrm{p}<.001$, also replicating prior research (Watson \& Morris, 1991).

\section{Study 3 Discussion}

Taken together, Study 3 found that while narcissism, perspective taking, and empathic concern all predicted more prosocial behaviors, more narcissistic people had different motives for volunteering than those who scored higher in perspective taking or empathic concern. The biggest difference was with respect to altruistic motives for volunteering, with more narcissistic people saying that they placed less importance on altruistic motives and with more empathic people (both perspective taking and empathic concern) placing more importance on altruistic motives when volunteering. More narcissistic people also placed marginally more importance on learning something new (Understanding) when volunteering, but this motive was unrelated to either type of empathy.

Both types of empathy were associated with placing greater important on altruistic motives. However, people scoring high in perspective taking had different motive profiles in other ways compared to those scoring high in empathic concern. Perspective taking was associated with slightly less important social and esteem motives, however, since these results changed in response to the covariates, they were less robust and will not be further discussed. Empathic concern, on the other hand, was consistently associated with less important social and career motives, even when including covariates. Although empathic concern was associated with slightly more important protective motives, these results were only marginally significant and thus will therefore not be discussed further.

\section{General Discussion}

Although much is known about the relationship between narcissism and antisocial behaviors, there is less research examining the relationship between narcissism and prosociality. In the current paper, we added to this growing literature by examining the relationship between narcissism and prosocial motives and self-reported behaviors. Taken together, the studies found that the prosociality of more narcissistic people depended upon the type of prosocial behavior and also the motive for engaging in it. 
For example, those who scored higher in narcissism, perspective taking, and empathic concern all reported that they tend to frequently engage in self-reported prosocial behavior, even when controlling for social desirability (Study 3). However, more narcissistic people may place less importance of behaving prosocially for altruistic reasons. Thus, people should not assume that if more narcissistic people are heavily involved in prosocial activities, that these are necessarily motivated by altruistic concerns.

With respect to volunteering specifically, perspective taking and empathy both predicted more importance of altruistic motives, however, narcissism was associated with less importance of altruistic motives for volunteering (Study 3). This finding replicated prior research (Brunell et al., 2014; Davis et al., 2003). The very same behavior (volunteering) is motivated quite differently depending on one's traits. In addition, more narcissistic people said they prefer to help people when others are watching, and not when anonymous (Study 2). This also replicated prior research (Eberly-Lewis \& Coetzee, 2015). We also examined how behaviors in the ice bucket challenge were related to narcissism. We found that more narcissistic people were less likely to donate money, but more likely to engage in 'slacktivism' by posting an online video of themselves pouring ice water over their head (Study 1). The fact that more narcissistic people prefer to give when there is an audience makes using the internet for prosocial behavior a natural fit, especially when it involves video posting or other attention grabbing stunts.

It is doubtful that more narcissistic people showed this unique pattern of prosociality because they wanted to appear more empathic or prosocial to others. Narcissism is either uncorrelated or negatively correlated with social desirability (Watson et al., 1984; Watson \& Morris, 1991). Social desirability scales include prosocial items such as "I never hesitate to go out of my way to help someone in trouble," so if narcissistic people cared about looking prosocial they should score higher on social desirability. Also, in Study 3, we found that the results remained virtually identical when controlling for social desirability, which is a novel contribution of this paper.

Instead, the Extended Agency Model may help to explain these results. It describes narcissism as prioritizing agency (e.g., status, power) over communion (e.g., warmth, connection), which creates characteristic interpersonal (e.g., self-promotion) and intrapersonal strategies (e.g. self-serving biases; Campbell \& Foster, 2007). It makes sense that people who prioritize agentic concerns would be strategic helpers who only help when it could help themselves in some way, such as by receiving direct reciprocation or by receiving something intangible such as attention, which is an important source of narcissistic esteem. Thus, narcissistic people should be more likely to participate in prosocial behaviors that are seen by others, which would increase the chance for receiving praise or attention for them. In contrast, people who prioritize communal concerns, such as more empathic people, seem to be more guided by others' needs when deciding to help, compared to more narcissistic people.

\section{Strengths, Limitations, and Future Directions}

We take a more comprehensive approach to prosociality than prior research by examining different kinds of prosocial behavior, including informal prosocial behavior (e.g., everyday acts of helping such as allowing a stranger to move ahead in line), and formal prosocial behavior (e.g., volunteering, charitable donations). Indeed, to our knowledge, the relationship between narcissism and charitable donations has received limited attention in prior research (Study 1). We also examined more psychological aspects of prosocial behaviors, such as the situations (Studies 1 and 2) and motives (Study 3) that elicit them. Overall, we found that behaviors themselves may be less important in identifying more narcissistic people, and instead, narcissism can better be 
identified through the situations (the presence of attention, rewards) and motives (low focus on others' needs) that elicit prosocial behaviors.

When interpreting our results, readers should be aware that they are based on nonrepresentative samples of predominantly female participants. Thus, we do not know if these results would generalize beyond the current samples to broader populations. However, when controlling for gender, we find that most of the results and conclusions from the three studies in this paper remain similar. Still, future research should examine whether narcissism predicts strategic helping behaviors among people of a variety of social, economic, and cultural backgrounds.

These studies also relied on self-reports of behaviors, and thus, future researchers should explore actual behaviors. Nearly all research to date focuses on self-reported prosocial behavior (Brunell et al., 2014; Eberly-Lewis \& Coetzee, 2015; Kauten \& Barry, 2014; Naderi \& Strutton, 2014; Zhou et al., 2010). However, one study used peer-reports of prosocial behaviors in addition to self-reports, finding that although more narcissistic people self-report more prosocial behaviors, their peers do not perceive them that way (Kauten \& Barry, 2014). It is easier to look good in self-report measures of prosocial behaviors, but there has been limited research measuring the actual prosocial behaviors of more narcissistic people. Although other important work relies on hypothetical dilemmas, it is still the most akin to behavior that currently exists. These studies have found that narcissism is associated with less contributions to the common good in a resource dilemma game (Brunell et al., 2013; Campbell et al., 2005).

Future research should also examine prosocial behaviors and motives among different forms of narcissism such as vulnerable narcissism, since the current studies only focused on grandiose narcissism. Grandiose and vulnerable narcissism share many features (e.g., need for admiration, self-focus, and inflated self-worth), however, as its name implies, vulnerable narcissism is also associated with negative emotions (e.g., shame), introversion, and evaluative concerns (Arble, 2008; Hendin \& Cheek, 1997). Considering that more vulnerable narcissistic people may be more worried about how others perceive them, the difference between selfreported and actual prosocial behaviors may be especially pronounced for them.

One limitation that is common to research on personality traits, is the correlational nature of the link between narcissism and prosociality. Although it is reasonable to assume that narcissism may causally affect prosocial motivations and behaviors, it is also possible that the experience of prosocial motivations and behaviors themselves can contribute to lower narcissism. Indeed, activating a communal focus can lead to decreases in narcissistic tendencies (Giacomin \& Jordan, 2014), and participating in prosocial behaviors can increase empathy (Yogev \& Ronen, 1982). Another consideration with correlational studies is the potential for third variables. In this paper, we were able to rule out social desirability as a potential explanation for our findings (Study 3), but other potential explanations remain.

One plausible explanation for the unique pattern of prosociality among people who score high in narcissism is that they take a more "rational actor" or "economic" approach to helping, seeing it as an exchange of their time and resources that warrants reciprocity in some form. With this explanation in mind, future studies should further examine under which conditions, and for which reasons, more narcissistic people help others. For example, researchers could experimentally manipulate the potential for various rewards, and then examine the relationship between narcissism and helping. Future studies could also allow participants to make these decisions in private versus in public. The Extended Agency Model would lead to the prediction that more narcissistic people will only help more when their helping decisions are public, 
because helping for more intrinsic reasons (i.e. out of altruistic concern) does not seem to be a priority for more narcissistic people.

There are some practical questions that could also be addressed in future research, with implications for nonprofit organizations. For example, researchers could vary other rewards that approximate real-life charitable giving, such as posting givers' names on the internet or receiving a small gift in return for their donation, to examine whether more narcissistic people are more likely to give in these circumstances. Moreover, because of their less-than-altruistic motives for volunteering, it would be important to ask whether more narcissistic people are less committed to their volunteering jobs in terms of working fewer hours per week and being more likely to leave. In addition, some research found that narcissism is associated with a higher need for power (Carroll, 1989; Gebauer, Sedikides, Verplanken, \& Maio, 2012). Thus, future research could examine whether more narcissistic people are more likely to select high power or leadership volunteer roles (e.g., announcer, spokesperson, board member) versus more behind-the-scenes volunteer roles (e.g., preparing food, planning events, stuffing envelopes).

Finally, other research has identified a relationship between motives for volunteering and health and well-being. This research has found that volunteers who prioritize other-oriented motive, such as altruistic values and social connection, experience better well-being and better physical health (i.e. lower mortality risk), compared to volunteers who prioritize receiving some sort of personal benefit such as increasing their self-esteem or avoiding feelings of guilt (Konrath, Fuhrel-Forbis, Lou, \& Brown, 2012; Stukas, Hoye, Nicholson, Brown, \& Aisbett, 2014). Thus, future research could examine whether narcissistic people are less likely to experience the "joy of giving," because of their less-than-altruistic motivations.

\section{Conclusion}

This paper addressed some gaps in the literature, but clearly, there is much to be learned about narcissism and prosociality. We know a lot about the undesirable behaviors associated with narcissism, such as aggressive behavior. We know comparatively very little about how, when, and why more narcissistic people engage in prosocial behaviors. What we do know, based on the results of this paper, is that when asking more narcissistic people for a favor, it may be best to mention what is in it for them. 
Table 1

Raw correlations between all measures in Study 2

\begin{tabular}{|c|c|c|c|c|c|c|c|c|c|}
\hline Measure & 1 & 2 & 3 & 4 & 5 & 6 & 7 & 8 & 9 \\
\hline \multicolumn{10}{|l|}{ 1. Narcissism } \\
\hline $\begin{array}{l}\text { 2. Volunteering } \\
\text { behavior }\end{array}$ & .02 & & & & & & & & \\
\hline $\begin{array}{l}\text { 3. Community } \\
\text { project } \\
\text { involvement }\end{array}$ & .08 & $.71^{* * *}$ & & & & & & & \\
\hline $\begin{array}{l}\text { 4. Public prosocial } \\
\text { behavior }\end{array}$ & $.22 * * *$ & -.02 & .07 & & & & & & \\
\hline $\begin{array}{l}\text { 5. Dire prosocial } \\
\text { behavior }\end{array}$ & .03 & .02 & .07 & $.19 * *$ & & & & & \\
\hline $\begin{array}{l}\text { 6. Emotional } \\
\text { prosocial behavior }\end{array}$ & $.10 \sim$ & .02 & .10 & $.14^{*}$ & $.62 * * *$ & & & & \\
\hline $\begin{array}{l}\text { 7. Compliant } \\
\text { prosocial behavior }\end{array}$ & -.09 & .10 & .08 & -.02 & $.49 * * *$ & $.55 * * *$ & & & \\
\hline $\begin{array}{l}\text { 8. Anonymous } \\
\text { prosocial behavior }\end{array}$ & -.05 & .02 & .09 & $.40 * * *$ & $.45^{* * *}$ & $.28 * * *$ & $.28 * * *$ & & \\
\hline $\begin{array}{l}\text { 9. Opportunistic } \\
\text { prosocial behavior }\end{array}$ & $.18^{* *}$ & -.05 & .05 & $.70 * * *$ & $.21^{* * *}$ & $.13^{*}$ & -.09 & $.42 * * *$ & \\
\hline M & 3.99 & 3.28 & 2.55 & 2.25 & 3.24 & 3.45 & 3.63 & 2.81 & 2.23 \\
\hline SD & .89 & 1.58 & 1.42 & .82 & .80 & .76 & .83 & .75 & .79 \\
\hline Range & $1.63-6.56$ & $1-7$ & $1-7$ & $1-5$ & $1-5$ & $1.5-5$ & $1.5-5$ & $1-5$ & $1-5$ \\
\hline
\end{tabular}

Note. $\sim \mathrm{p}<.10,{ }^{*} \mathrm{p}<.05,{ }^{* *} \mathrm{p}<.01, * * * \mathrm{p}<.001$. 
STRATEGIC HELPER

Table 2

Results of a regression analysis examining the independent relationships between the prosocial variables and narcissism in Study 2

\begin{tabular}{lcc}
\hline & \multicolumn{2}{c}{ Narcissism (outcome) } \\
\cline { 2 - 3 } Prosocial measures (predictors) & Overall & $\begin{array}{c}\text { Adjusted } \\
\text { (controlling for } \\
\text { gender) }\end{array}$ \\
\hline Frequency of volunteer work & -.01 & -.01 \\
Frequency of community project involvement & .08 & .09 \\
Public prosocial behaviors & $.20^{*}$ & $.17^{*}$ \\
Dire prosocial behaviors & .00 & -.01 \\
Emotional prosocial behaviors & $.17^{*}$ & $.21^{*}$ \\
Compliant prosocial behaviors & $-.13^{*}$ & $-.13^{\sim}$ \\
Anonymous prosocial behaviors & $-.18^{*}$ & $-.17^{*}$ \\
Opportunistic prosocial behaviors & .07 & .07 \\
\hline
\end{tabular}

Note. Standardized betas are reported in this table. Z-scores were calculated to create comparable scales for the analysis. $\sim \mathrm{p}<.10,{ }^{*} \mathrm{p}<.05,{ }^{* *} \mathrm{p}<.01,{ }^{* * *} \mathrm{p}<.001$. 
Table 3

Raw correlations between all measures in Study 3

\begin{tabular}{|c|c|c|c|c|c|c|c|c|c|c|}
\hline & 1 & 2 & 3 & 4 & 5 & 6 & 7 & 8 & 9 & 10 \\
\hline \multicolumn{11}{|l|}{ 1. Narcissism } \\
\hline 2. Perspective Taking & $-.15^{* * *}$ & & & & & & & & & \\
\hline 3. Empathic Concern & $-.18 * * *$ & $.52 * * *$ & & & & & & & & \\
\hline $\begin{array}{l}\text { 4. Frequency of } \\
\text { prosocial behaviors }\end{array}$ & $.16 * * *$ & $.17 * * *$ & $.20 * * *$ & & & & & & & \\
\hline $\begin{array}{l}\text { 5. Altruistic motives for } \\
\text { volunteering }\end{array}$ & $-.15^{* * *}$ & $.31 * * *$ & $.59 * * *$ & $.16^{* * *}$ & & & & & & \\
\hline $\begin{array}{l}\text { 6. Social motives for } \\
\text { volunteering }\end{array}$ & -.04 & $.09 *$ & $.16^{* * *}$ & $.12 * *$ & $.38 * * *$ & & & & & \\
\hline $\begin{array}{l}\text { 7. Career motives for } \\
\text { volunteering }\end{array}$ & .03 & .04 & .01 & .02 & $.24 * * *$ & $.30 * * *$ & & & & \\
\hline $\begin{array}{l}\text { 8. Esteem motives for } \\
\text { volunteering }\end{array}$ & -.02 & $.11^{* *}$ & $.28 * * *$ & $.11^{* *}$ & $.54 * * *$ & $.46^{* * *}$ & $.45 * * *$ & & & \\
\hline $\begin{array}{l}\text { 9. Protective motives for } \\
\text { volunteering }\end{array}$ & .00 & $.10 * *$ & $.19 * * *$ & $.18^{* * *}$ & $.33 * * *$ & $.47 * * *$ & $.41 * * *$ & $.62 * * *$ & & \\
\hline $\begin{array}{l}\text { 10. Understanding } \\
\text { motives for volunteering }\end{array}$ & .00 & $.19 * * *$ & $.32 * * *$ & $.18^{* * *}$ & $.59 * * *$ & $.53 * * *$ & $.49 * * *$ & $.60 * * *$ & $.50 * * *$ & \\
\hline M & 4.35 & 3.56 & 3.83 & 2.42 & 5.00 & 3.74 & 3.85 & 4.07 & 3.24 & 4.38 \\
\hline SD & 3.09 & .64 & .63 & .58 & 1.02 & 1.36 & 1.55 & 1.33 & 1.44 & 1.13 \\
\hline Range & $0-14$ & $1.4-5.0$ & $1.6-5.0$ & $1.0-5.2$ & $1-6$ & $1-6$ & $1-6$ & $1-6$ & $1-6$ & $1-6$ \\
\hline
\end{tabular}


Table 4

Results of three separate regression analyses examining the independent relationships between the prosocial variables and narcissism, perspective taking, and empathic concern in Study 3

\begin{tabular}{lcccccc}
\hline & \multicolumn{2}{c}{$\begin{array}{c}\text { Narcissism } \\
\text { (outcome) }\end{array}$} & $\begin{array}{c}\text { Perspective Taking } \\
\text { (outcome) }\end{array}$ & \multicolumn{2}{c}{$\begin{array}{c}\text { Empathic Concern } \\
\text { (outcome) }\end{array}$} \\
\cline { 2 - 7 } $\begin{array}{l}\text { Prosocial measures } \\
\text { (predictors) }\end{array}$ & Overall & Adjusted & Overall & Adjusted & Overall & Adjusted \\
\hline $\begin{array}{l}\text { Frequency of prosocial } \\
\text { behaviors }\end{array}$ & $.18^{* * *}$ & $.18^{* * *}$ & $.13^{* * *}$ & $.11^{* *}$ & $.11^{* * *}$ & $.10^{* * *}$ \\
Altruistic motives & $-.26^{* * *}$ & $-.20^{* * *}$ & $.32^{* * *}$ & $.28^{* * *}$ & $.60^{* * *}$ & $.56^{* * *}$ \\
Social motives & -.04 & -.05 & -.05 & $-.07 \sim$ & $-.09^{* *}$ & $-.09^{* *}$ \\
Career motives & .04 & .04 & -.03 & -.01 & $-.15^{* * *}$ & $-.15^{* * *}$ \\
$\begin{array}{l}\text { Esteem motives } \\
\text { Protective motives }\end{array}$ & .05 & .05 & $-.09 \sim$ & -.07 & -.02 & -.01 \\
Understanding & -.03 & -.02 & .03 & .04 & $.07 \sim$ & $.07 \sim$ \\
motives & $.10 \sim$ & $.11^{*}$ & .06 & .06 & .05 & .04 \\
\hline
\end{tabular}

Note. Standardized betas are reported in this table. Z-scores were calculated to create comparable scales for the analysis. Adjusted models controlled for gender and social desirability. $\sim \mathrm{p}<.10$, ${ }^{*} \mathrm{p}<.05, * * \mathrm{p}<.01, * * * \mathrm{p}<.001$. 


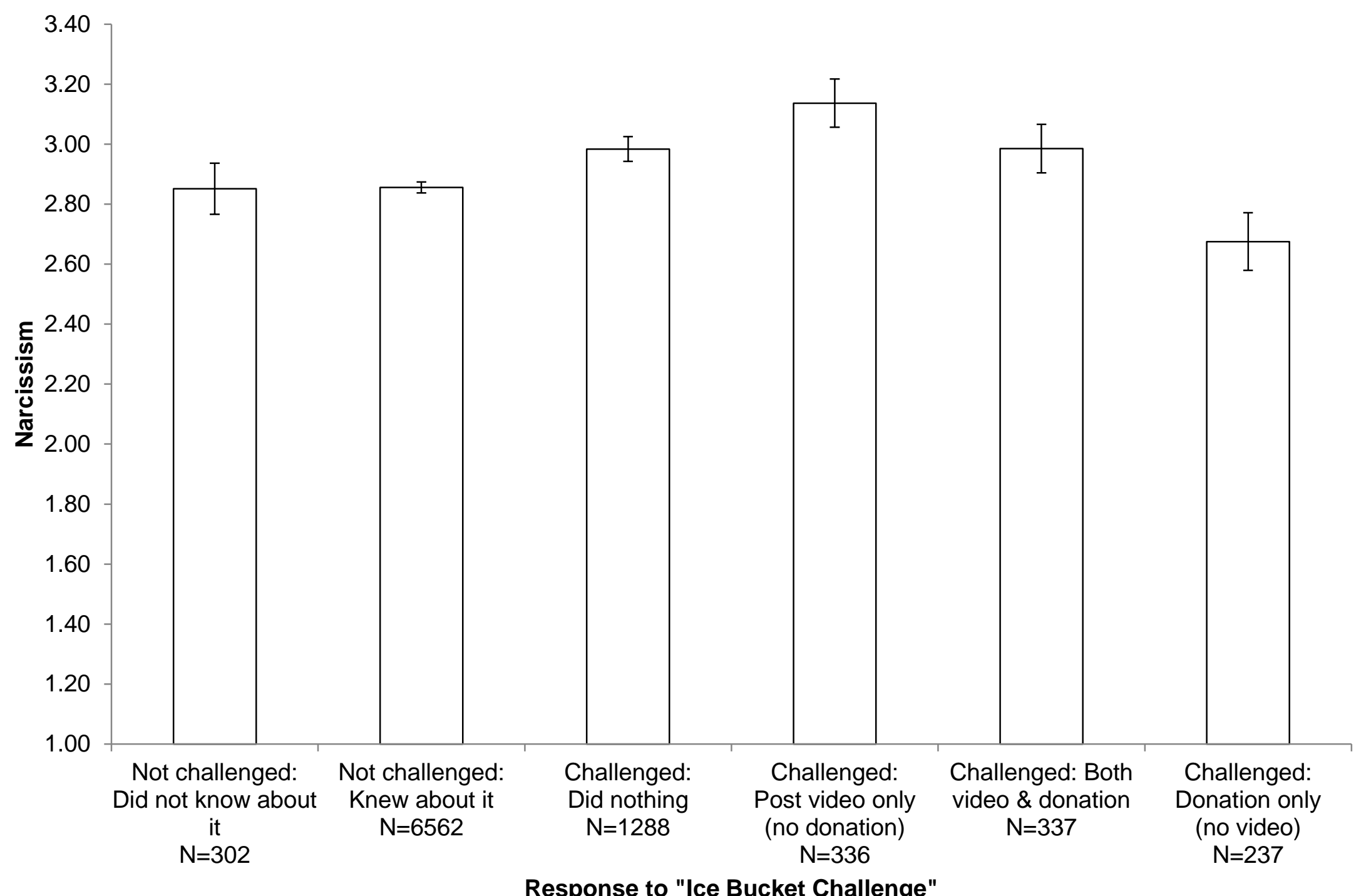

Figure 1. Narcissism scores dependent on participants’ responses to the “ice bucket challenge” in Study 1. 
Compliance with Ethical Standards:

Funding: This project was supported by grants from the John Templeton Foundation (\#47993 and 57942) and Wake Forest University, The Character Project.

Ethical approval: All procedures performed in studies involving human participants were in accordance with the ethical standards of the institutional and/or national research committee and with the 1964 Helsinki declaration and its later amendments or comparable ethical standards.

Informed consent: Informed consent was obtained from all individual participants included in Studies 2 and 3. Study 1 was an exempt study that relied on an existing de-identified dataset. 
STRATEGIC HELPER

\section{References}

Ames, D. R., Rose, P., \& Anderson, C. P. (2006). The NPI-16 as a short measure of narcissism. Journal of Research in Personality, 40(4), 440-450. doi: 10.1016/j.jrp.2005.03.002

Arble, E. P. (2008). Evaluating the psychometric properties of the hypersensitive narcissism scale: Implications for the distinction of covert and overt narcissism. (Master of Science), Eastern Michigan University, Ypsilanti, MI.

Batson, C. D. (2011). Altruism in humans: Oxford University Press.

Batson, C. D., \& Powell, A. (2003). Altruism and prosocial behavior. In T. Millon \& M. Lerner (Eds.), Handbook of Psychology. Personality and Social Psychology (Vol. Vol. 5). Hoboken, NJ: John Wiley \& Sons, Inc.

Borman, W. C., Penner, L. A., Allen, T. D., \& Motowidlo, S. J. (2001). Personality predictors of citizenship performance. International Journal of Selection and Assessment, 9(1-2), 5269.

Brunell, A. B., Davis, M. S., Schley, D. R., Eng, A. L., van Dulmen, M. H. M., Wester, K. L., \& Flannery, D. J. (2013). A new measure of interpersonal exploitativeness. Frontiers in psychology, 4. doi: 299

10.3389/fpsyg.2013.00299

Brunell, A. B., Tumblin, L., \& Buelow, M. T. (2014). Narcissism and the Motivation to Engage in Volunteerism. Current Psychology, 33(3), 365-376.

Bushman, B. J., \& Baumeister, R. F. (1998). Threatened Egotism, Narcissism, Self-Esteem, and Direct and Displaced Aggression: Does Self-Love or Self-Hate Lead to Violence? Journal of Personality and Social Psychology, 75(1), 219-229.

Campbell, W. K., Bush, C. P., Brunell, A. B., \& Shelton, J. (2005). Understanding the Social Costs of Narcissism: The Case of the Tragedy of the Commons. Personality and Social Psychology Bulletin, 31(10), 1358-1368. doi: 10.1177/0146167205274855

Campbell, W. K., \& Foster, C. A. (2002). Narcissism and Commitment in Romantic Relationships: An Investment Model Analysis. Personality and Social Psychology Bulletin, 28(4), 484-495. doi: 10.1177/0146167202287006

Campbell, W. K., \& Foster, J. D. (2007). The narcissistic self: Background, an extended agency model, and ongoing controversies. The self, 115-138.

Campbell, W. K., Rudich, E. A., \& Sedikides, C. (2002). Narcissism, Self-Esteem, and the Positivity of Self-Views: Two Portraits of Self-Love. Personality and Social Psychology Bulletin, 28(3), 358-368. doi: 10.1177/0146167202286007

Carlo, G., \& Randall, B. A. (2002). The development of a measure of prosocial behaviors for late adolescents. Journal of youth and adolescence, 31(1), 31-44.

Carroll, L. (1989). A comparative study of narcissism, gender, and sex-role orientation among bodybuilders, athletes, and psychology students. Psychological Reports, 64(3), 999-1006.

Clary, E. G., Snyder, M., Ridge, R. D., Copeland, J., Stukas, A. A., Haugen, J., \& Miene, P. (1998). Understanding and Assessing the Motivations of Volunteers: A Functional Approach. Journal of Personality and Social Psychology, 74(6), 1516-1530.

Davis, M. (1983). Measuring individual differences in empathy: Evidence for a multidimensional approach. Journal of Personality and Social Psychology, 44(1), 113-126. doi: 10.1037/0022-3514.44.1.113

Davis, M., Hall, J. A., \& Meyer, M. (2003). The First Year: Influences on the Satisfaction, Involvement, and Persistence of New Community Volunteers. Personality and Social Psychology Bulletin, 29(2), 248-260. doi: 10.1177/0146167202239050 
Eagly, A. H. (2009). The his and hers of prosocial behavior: An examination of the social psychology of gender. American Psychologist, 64(8), 644-658.

Eberly-Lewis, M. B., \& Coetzee, T. M. (2015). Dimensionality in adolescent prosocial tendencies: Individual differences in serving others versus serving the self. Personality and Individual Differences, 82, 1-6.

Eisenberg, N., \& Miller, P. A. (1987). The relation of empathy to prosocial and related behaviors. Psychological Bulletin, 101(1), 91.

Facebook.com. (2014). The Ice Bucket Challenge on Facebook (9/7/14) Accessed 8/20/2015 at http://newsroom.fb.com/news/2014/08/the-ice-bucket-challenge-on-facebook/.

Ferriday, C., Vartanian, O., \& Mandel, D. R. (2011). Public but not private ego threat triggers aggression in narcissists. European Journal of Social Psychology, 41(5), 564-568.

Foster, J. D., Keith Campbell, W., \& Twenge, J. M. (2003). Individual differences in narcissism: Inflated self-views across the lifespan and around the world. Journal of Research in Personality, 37(6), 469-486.

Fukunishi, I., Hattori, M., Nakamura, H., \& Nakagawa, T. (1995). Hostility is related to narcissism controlling for social desirability: Studies of college students and patients with myocardial infarction. Journal of Psychosomatic Research, 39(2), 215-220.

Gebauer, J. E., Sedikides, C., Verplanken, B., \& Maio, G. R. (2012). Communal narcissism. Journal of Personality and Social Psychology, 103(5), 854.

Giacomin, M., \& Jordan, C. H. (2014). Down-Regulating Narcissistic Tendencies: Communal Focus Reduces State Narcissism. Personality and Social Psychology Bulletin, 40(4), 488500. doi: 10.1177/0146167213516635

Grühn, D., Rebucal, K., Diehl, M., Lumley, M., \& Labouvie-Vief, G. (2008). Empathy across the adult lifespan: Longitudinal and experience-sampling findings. Emotion, 8(6), 753.

Hendin, H. M., \& Cheek, J. M. (1997). Assessing hypersensitive narcissism: A reexamination of Murray's Narcism Scale. Journal of Research in Personality, 31(4), 588-599.

Kauten, R., \& Barry, C. T. (2014). Do you think I'm as kind as I do? The relation of adolescent narcissism with self-and peer-perceptions of prosocial and aggressive behavior. Personality and Individual Differences, 61, 69-73.

Konrath, S., Bushman, B., \& Campbell, W. K. (2006). Attenuating the link between threatened egotism and aggression. Psychological Science, 17(11), 995-1001. doi: PSCI1818 [pii]10.1111/j.1467-9280.2006.01818.x

Konrath, S., Corneille, O., Bushman, B. J., \& Luminet, O. (2014). The relationship between narcissistic exploitativeness, dispositional empathy, and emotion recognition abilities. Journal of Nonverbal Behavior, 38(1), 129-143.

Konrath, S., Fuhrel-Forbis, A., Lou, A., \& Brown, S. L. (2012). Motives for Volunteering Are Associated with Mortality Risk in Older Adults. Health Psychology, 31(1), 87-96.

Konrath, S., Meier, B., \& Bushman, B. (2014). Development and validation of the Single Item Narcissism Scale (SINS). PLoS ONE, 9(8), e103469.

Kristofferson, K., White, K., \& Peloza, J. (2014). The nature of slacktivism: How the social observability of an initial act of token support affects subsequent prosocial action. Journal of Consumer Research, 40(6), 1149-1166.

Miller, J. D., \& Campbell, W. K. (2008). Comparing Clinical and Social-Personality Conceptualizations of Narcissism. Journal of Personality, 76(3), 449-476. 
Munk, C. (2014). Ice Bucket Donations Continue to Rise: \$94.3 Million Since July 29. ALS Association. http://www.alsa.org/news/media/press-releases/ice-bucket-challenge082714.html

Naderi, I., \& Strutton, D. (2014). Can normal narcissism be managed to promote green product purchases? Investigating a counterintuitive proposition. Journal of Applied Social Psychology, 44(5), 375-391. doi: 10.1111/jasp.12230

O’Brien, E., Konrath, S. H., Grühn, D., \& Hagen, A. L. (2013). Empathic concern and perspective taking: Linear and quadratic effects of age across the adult life span. The Journals of Gerontology Series B: Psychological Sciences and Social Sciences, 68(2), 168-175.

Paulhus, D., \& John, O. P. (1998). Egoistic and moralistic biases in self-perception: The interplay of self-deceptive styles with basic traits and motives. Journal of Personality, 66(6), 1025-1060.

Paulhus, D., \& Reid, D. B. (1991). Enhancement and denial in socially desirable responding. Journal of Personality and Social Psychology, 60(2), 307.

Reidy, D. E., Zeichner, A., Foster, J. D., \& Martinez, M. A. (2008). Effects of narcissistic entitlement and exploitativeness on human physical aggression. Personality and Individual Differences, 44(4), 865-875.

Smith, T., Marsden, P., Hout, M., \& Kim, J. (2013). General Social Surveys, 1972-2012 [machine-readable data file]. Sponsored by National Science Foundation. --NORC ed.-Chicago: National Opinion Research Center [producer]; Storrs, CT: The Roper Center for Public Opinion Research, University of Connecticut [distributor].

Strahan, R., \& Gerbasi, K. C. (1972). Short, homogeneous versions of the Marlow-Crowne Social Desirability Scale. Journal of Clinical Psychology, 28(2), 191-193. doi: 10.1002/1097-4679(197204)28:2<191::aid-jclp2270280220>3.0.co;2-g

Stukas, A. A., Hoye, R., Nicholson, M., Brown, K. M., \& Aisbett, L. (2014). Motivations to Volunteer and Their Associations With Volunteers' Well-Being. Nonprofit and Voluntary Sector Quarterly, 0899764014561122.

Twenge, J., \& Campbell, W. K. (2003). “Isn't It Fun to Get the Respect That We're Going to Deserve?” Narcissism, Social Rejection, and Aggression. Personality and Social Psychology Bulletin, 29(2), 261-272. doi: 10.1177/0146167202239051

Underwood, B., \& Moore, B. (1982). Perspective-taking and altruism. Psychological Bulletin, 91(1), 143.

Wallace, H. M., \& Baumeister, R. F. (2002). The performance of narcissists rises and falls with perceived opportunity for glory. Journal of Personality and Social Psychology, 82(5), 819.

Watson, P., Grisham, S., Trotter, M., \& Biderman, M. (1984). Narcissism and empathy: validity evidence for the Narcissistic Personality Inventory. Journal of Personality Assessment, 48(3), 301-305.

Watson, P., \& Morris, R. J. (1991). Narcissism, empathy and social desirability. Personality and Individual Differences, 12(6), 575-579.

Yogev, A., \& Ronen, R. (1982). Cross-Age Tutoring: Effects on Tutors' Attributes. Journal of Educational Research, 75(5), 261-268.

Zhou, H., Zhou, H., \& Zhang, B. (2010). Relationships among narcissism, empathy, and prosocial behaviours. Chinese Journal of Clinical Psychology, 18(2), 228-231. 